\title{
Introduction to $2017-4$
}

lobalization, rising inequality, polarization, lack of trust, unpredictability, deregulation, destabilization, fragmentation, and flux in working life - and in society in general - seems to be signs of our time. Social scientists have characterized these signs as the postmodern condition, late modernity, liquid modernity, etc., and described how these processes are transforming both our societal institutions and social life in general in undesirable ways. However, in this gloomy characterization of our times, many have been looking toward the Nordic societies to find inspiration for welfare models that might stem the tide of societal disintegration and bring hope of solidarity, social cohesion, regulation, and temper capitalism. The Nordic societies have served as exemplary cases to be emulated by Third Way and progressive politics around the world.

No doubt, seen by international standards, the Nordic societies stand out in positive ways. But how have the Nordic societies been doing lately? Are there still reasonable grounds for looking toward the Nordic societies in order to find hope and inspiration? Detailed and thorough studies of working life in the Nordic countries have appeared in this journal, and the present issue adds new empirical material that helps us appreciate the complexities and nuances of the unfolding of working life in contemporary Nordic societies.

This issue starts with an article on wage inequality in the Norwegian context written by Håvard Helland, Thijs Bol, and Ida Drage. The authors observe a slight increase in wage inequality in Norway during the last decade and they set out to investigate the nature of this development. Their findings suggest that the inequality - although the increase is only slight - primarily can be attributed to between-occupational wage inequality, whereas within-occupational inequality is not as significant. The development in Norway thus seems to follow the tendencies previously detected in more liberal economies, for example, in the UK and US.

The second article, 'Significance of Monitoring and Control for Employees' Felt Trust, Motivation and Mastery' written by Vilde Hoff Bernstrøm and Helge Svare investigates another significant and characteristic element of (Nordic) working life, namely the role of 'trust'. Focusing on felt trust, the article studies how Norwegian employees' felt trust is related to monitoring, control over decisions, motivation, and experience of mastery in work. The authors argue that felt trust can be seen as a mediator between various organizational practices, the employees' intrinsic motivation, and wellbeing at work.

Vocational guidance and the possibility of predicting vocational choices have come to play a central role in the Nordic welfare societies. In 'Antecedents of Norwegian Adolescents' Choice of Educational Pathway in Hospitality and Tourism', Åse Helene Bakkevig Dagsland, Reidar J. Mykletun, and Ståle Valvatne Einarsen investigate how adolescents in Norway think and feel about the line of work characteristic of the

\footnotetext{
$\overline{{ }^{1} \text { You can find this text and its DOI at https://tidsskrift.dk/njwls/index. }}$
} 
hospitality industry, and sets out to identify the beliefs, behavioral intentions, and background factors that can predict the youngsters' choice of vocational foundation classes for high school related to the industry.

Navigating in working life and balancing work, family, caregiving, ambitions, etc. is an achievement that can be accomplished in many different ways. In the article 'Parttime or Full-time Employment - Choices and Constraints', Kari Ingstad and Marianne Hedlund set out to investigate the working hour patterns of nurses in Norway in interactions among the welfare state, the labor market, and family-life practices. In and among these complex contexts, the nurses construct their career patterns in flexible ways.

In the two last articles of this issue, we move from a Norwegian to a Swedish context to learn about work in the health care sector. In their article 'Empoyees' Conceptions of Coworkership in a Swedish Health Care Organization', Caroline Bergman, Jesper Löve, Annemarie Hultberg, and Katrin Skagert explore how the Scandinavian concept of 'co-workership' is interpreted differently among employees in the contemporary Swedish health care sector. Interpretations cover a broad register of ideals and conceptions related to intra- and interprofessional cooperation such as group coherence, cooperation over boundaries, mutual trust of competence, social climate, and community. Characteristically, the conceptions were predominantly formed in relation to the collective work process around the patient - and did not explicitly include the role of management. Finally, Magnus Granberg in his article 'Shop Floor Power: Opportunity and Collectivism in Nurses' Collective Resignations' investigates the phenomenon of collective resignation by registered nurses in the Swedish health care service. Collective resignation has been used by Swedish nurses as an effective means of worker action, and Grandberg explores how this collective action is utilized to strengthen shop floor power.

In these six fascinating accounts of aspects of contemporary working life in Nordic countries, we see how individuals and collectives are struggling to secure wages, to uphold trust, to navigate career paths and working hours, and to find new interpretations of collectivism and the strategies of collective action. Whether these struggles are successful in stemming the tide of 'liquid modernity' is an open question. But the careful studies of contemporary working life given in the six articles can help us form a nuanced picture of the challenges that we are facing.

Anders Buch 